\title{
Aerospace Vehicle Simulation and Analysis Applying Pure Pursuit Guidance Method
}

\author{
Ahmed I. Saleh \\ Mansoura University Egypt
}

\author{
Ali Takieldeen \\ IEEE Senior Member \\ Alexandria University Egypt
}

\author{
Ahmed R. El-Sawi \\ Mansoura University Egypt
}

\begin{abstract}
In this paper we study aerospace vehicle motion in three dimensions. We formulate three degree of freedom kinematic equations of motion using pure pursuit guidance method. which is known as path planning algorithm and it was stretched well beyond its intended usage by many aerospace applications also it is used to accomplish goal-seeking and path tracking. we solve the kinematic three degree of freedom equations of motion by numerical integration to make simulation using Matlab program .
\end{abstract}

\section{Keywords}

pure pursuit, guidance method, analytical form, numerical solution, mathematical model

\section{INTRODUCTION}

Aerospace vehicle is known as Unmanned Aerial Vehicles (UAVs) which have proven their usefulness in military applications in recent years. Large UAVs such as the General Dynamics Predator (27foot wingspan) [1] have become an integral part of the U.S. arsenal. Since 1994, the Predator has logged more than 20,000 flight hours, executing surveillance and tactical missions in virtually every part of the world. The military is also making use of smaller UAVs, known as mini UAVs. The Aero Vironment Pointer Mini-UAV was one of the first Mini UAVs deployed [2]. It has been used all over the world by small military units

as a short range video reconnaissance platform. It has a cost of $\$ 88,000$ [3], relatively low in comparison with the Predator's price tag of $\$ 50$ million. The Pointer has proven itself robust and reliable, but it does have disadvantages. This UAV is designed to be "man-packable" but the UAV is heavy and cumbersome for one person to carry. Its 9- foot wingspan also makes it easily visible to the enemy at the low altitudes it flies. Hence, the armed forces have made a significant push to develop a replacement for Pointer. This effort has lead to the Dragon Eye Mini UAV. The Dragon Eye is smaller and lighter than Pointer. However, Dragon Eye is still large enough (4 foot wing span) [4] to be visible to the enemy and requires a 2-man crew to transport and operate. There is room for improvement in the areas of UAV size and portability.

\section{GUIDED MISSILE PURPOSE AND} APPLICATIONS

Guided Missile is defined as an aerospace vehicle: In the guided class of missiles belong the aerodynamic guided missiles. That is, those missiles that use aerodynamic lift to control its direction of flight. An aerodynamic guided missile can be defined as an aerospace vehicle, with varying guidance capabilities, that is self-propelled through the atmosphere for the purpose of inflicting damage on a designated target. Stated another way, an aerodynamic guided missile is one that has a winged configuration and is usually Guided missile has been used in scientific application such as: fired in a direction approximately towards a designated target and subsequently receives steering commands from the ground guidance system (or its own, onboard guidance, system) to improve its accuracy. Guided missiles may either home to the target, or follow a nonhoming preset course. Homing missiles maybe active, semiactive, or passive. Nonhoming guided missiles are either inertially guided or preprogrammed $[5,6,7]$.

Guided missile civilian applications.

- 1-communications missiles.

- 2-surveillance missiles.

- 3-space research missiles.

and also widely used in military applications such as :

- 1-air to air missiles.

- 2-air to surface missiles.

- 3-surface to surface missiles.

- 4-surface to air missiles.

\section{GUIDANCE PROCESS}

Guidance is the means by which a missile steers, or is steered, to a target. A guided missile is guided according to a certain guidance law. In this chapter we consider homing guidance systems [8]. An autopilot is a closed-loop system inside the main guidance subsystem that ensures that the missile achieves accelerations as commanded and maintains stability

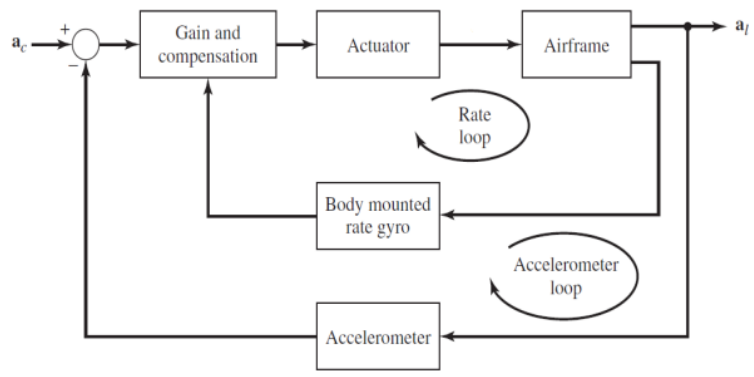

Figure 1: Typical autopilot configration

The design of an autopilot must be tailored to each individual missile airframe configuration and its associated aerodynamic characteristics, which are nonlinear functions of missile velocity, angle of attack, control surface deflection, and altitude. Therefore, a properly designed autopilot provides a nearly linear response characteristic if changes in these parameters about their nominal design values are small.

It should be pointed out, however, that there are some missile designs that do not require an autopilot. The most important nonlinear characteristic associated with the airframe is 
acceleration saturation, which occurs when the missile attempts to pull a large angle of attack. It is desirable to avoid a large angle of attack, since the associated drag results in a rapid loss of missile velocity. Furthermore, the airframe structural limit must not be exceeded. It is common practice in missile design to limit the commanded lateral acceleration in order to prevent both angle-of-attack saturation and structural failure. Therefore, autopilot command limiting is assumed

to be the dominant nonlinear effect, and all other nonlinear characteristics, such as actuator angle and angle rate limiting, aerodynamic nonlinearities, and instrumentation nonlinearities, are assumed to be secondary or equivalently represented as acceleration-limiting, or as changes in autopilot dynamics. The resulting model is therefore simple and generally applicable to a wide range of missile systems, and

captures what is known to be a dominant nonlinear system characteristic and an important factor in miss distance: lateral acceleration. A realistic autopilot can be designed that requires knowledge of very few

specific aerodynamic parameters, yet its response characteristics are easily related to the important missile aerodynamic properties. Figure 1 illustrates a block diagram of a generic autopilot, which uses accelerometer feedback in order to control the lateral acceleration of the missile $[7,9,10]$

\section{MATHEMATICAL MODEL APPLYING PURE PURSUIT GUIDANCE METHOD}

For two hundred years, pure pursuit was a source of delight to mathematicians, especially to amateurs of recreational mathematics. A great number of articles, papers, and notes have been published :an excellent historical review is Clarinval's, published under the auspices of UNESCO [11]. The four articles by Bernhart form an outstanding treatise [1213]. Pursuit curves seem to be aesthetically pleasant and to have inspired some 'mathematical art' [14,15]. A few modern references are given by Bruckstein in a very special paper [16].

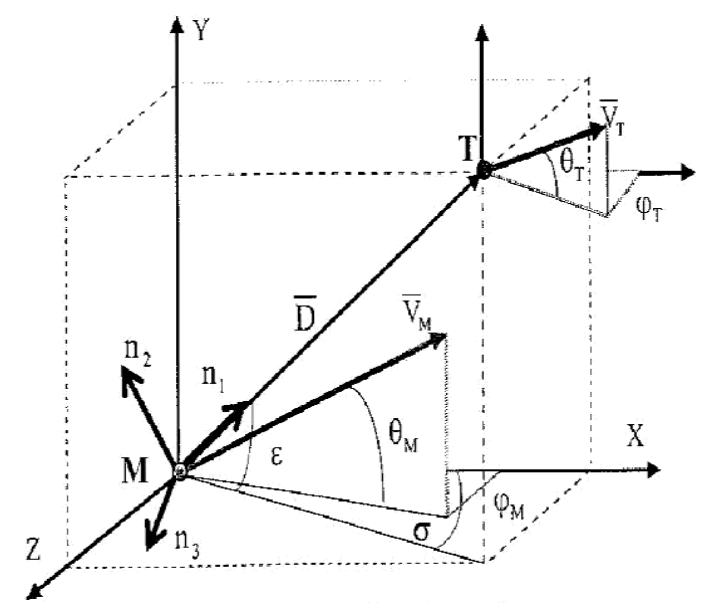

Figure2: Attitudes and coordinates of missile and target.

According to figure (2) the kinematic equations of motions will be proofed analytically by applying pure pursuit guidance method by decreasing the distance (D) between the missile and the target function in time parameter (integration ).

$\frac{\mathrm{d} \overline{\mathrm{D}}}{\mathrm{dt}}=\overline{\mathrm{V}}_{\mathrm{T}}-\overline{\mathrm{V}}_{\mathrm{M}}$

Where;
$\overline{\mathrm{D}}$ Distance vector between two vehicles.

$\overline{\mathrm{Vt}}$ Target velocity vector.

$\overline{\mathrm{Vm}}$ Missile velocity vector.

Where $\mathrm{T}$ represents the target position, $\mathrm{M}$ represents the missile position, is the target velocity, $\mathrm{V}$ is the missile velocity and $\mathrm{D}$ is the distance between the target and missile. Both magnitude and direction of the vector are functions of time. Thus, the first derivative of $\mathrm{D}$ has the form:

$\frac{d \bar{D}}{d t}=\frac{d\left\{D \widehat{D}_{0}\right\}}{d t}=\frac{d \bar{D}}{d t} \widehat{D}_{0}+\frac{d \widehat{D}_{0}}{d t} D$

Where the first term $\left(\frac{d \bar{D}}{d t} \widehat{D}_{0}\right)$ represent rate of change in magnitude and the second term $\left(\frac{\mathrm{d}_{0}}{\mathrm{dt}}\right) \mathrm{D}$ represent rate of change in direction.

$\frac{\mathrm{d} \overline{\mathrm{D}}}{\mathrm{dt}}=\frac{\mathrm{dD}}{\mathrm{dt}} \widehat{\mathrm{D}}_{0}+\overline{\mathrm{w}}_{\mathrm{D}} \otimes \overline{\mathrm{D}}$

$\frac{\mathrm{d} \overline{\mathrm{D}}}{\mathrm{dt}}=\dot{\mathrm{D}} \widehat{\mathrm{D}}_{0}+\overline{\mathrm{w}} \otimes \overline{\mathrm{D}}$

where $\omega$ is the angular rate of change of the LOS. Thus, the vector form (1) can be replaced by the component form in the radial direction and two normal directions as follows:

$\overline{\mathrm{V}}_{\mathrm{T}}-\overline{\mathrm{V}}_{\mathrm{M}}=\dot{\mathrm{D}} \widehat{\mathrm{D}}_{0}+\overline{\mathrm{w}} \otimes \overline{\mathrm{D}}(3)$

It follows from eq (3) that the motion of a missile to the target can be limited in the radial direction and in two normal directions. The scalar kinematic equations are obtained by specifying a reference frame along its axes the vector form (3) is projected. Since the objective is to minimize the distance between missile and target to zero. then by analyzing (w) the angular rate of change of the LOS from Figure 3.

$\overline{\mathrm{W}}=-\dot{\sigma} \sin \varepsilon \hat{\mathrm{n}}_{1}-\dot{\sigma} \cos \varepsilon \widehat{\mathrm{n}}_{2}+\dot{\varepsilon} \hat{\mathrm{n}}_{3}$

By applying cross product.

$\overline{\mathrm{W}} \otimes \overline{\mathrm{D}}=\left|\begin{array}{ccc}\hat{\mathrm{n}}_{1} & \hat{\mathrm{n}}_{2} & \hat{\mathrm{n}}_{3} \\ -\dot{\sigma} \sin \varepsilon & -\dot{\sigma} \cos \varepsilon & \dot{\varepsilon} \\ \mathrm{D} & 0 & 0\end{array}\right|$

$\overline{\mathrm{w}} \otimes \overline{\mathrm{D}}=\mathrm{D} \dot{\varepsilon} \hat{\mathrm{n}}_{2}+\mathrm{D} \dot{\sigma} \cos \varepsilon \hat{\mathrm{n}}_{3}(4)$

Substitute from (4) in (1) .

$\frac{d \bar{D}}{d t}=\dot{D} \hat{n}_{1}+D \dot{\varepsilon} \hat{n}_{2}+D \dot{\sigma} \cos \varepsilon \hat{n}_{3}$

By applying Pure pursuit guidance law.

$\varepsilon-\theta_{\mathrm{M}}=0$

$\sigma-\varphi_{\mathrm{M}}=0$

Final formula for the equations of motion form.

$$
\begin{aligned}
\dot{\mathrm{D}}=\mathrm{V}_{\mathrm{T}} \cos \left(\varepsilon-\theta_{\mathrm{T}}\right)-\mathrm{V}_{\mathrm{M}} \cos \left(\varepsilon-\theta_{\mathrm{M}}\right) \\
\mathrm{D} \varepsilon=\mathrm{V}_{\mathrm{M}} \sin \left(\varepsilon-\theta_{\mathrm{M}}\right)-\mathrm{V}_{\mathrm{T}} \sin \left(\varepsilon-\theta_{\mathrm{T}}\right)
\end{aligned}
$$

\section{RESULTS AND DISCUSSIONS}

- To solve the equations of motion, the numerical integration is used by using Euler method.

- MATLAB code is constructed to simulate flight path trajectory.

- The table displays the initial conditions 
Table 1: initial conditions

\begin{tabular}{|l|l|}
\hline Initial distance & $90 \mathrm{~km}$ \\
\hline Horizontal angle & 35 Degree \\
\hline Vertical angle & 25 Degree \\
\hline Missile velocity & $500 \mathrm{~m} / \mathrm{sec}$ \\
\hline Target velocity & $350 \mathrm{~m} / \mathrm{sec}$ \\
\hline
\end{tabular}

Trajectory simulation using MATLAB program.

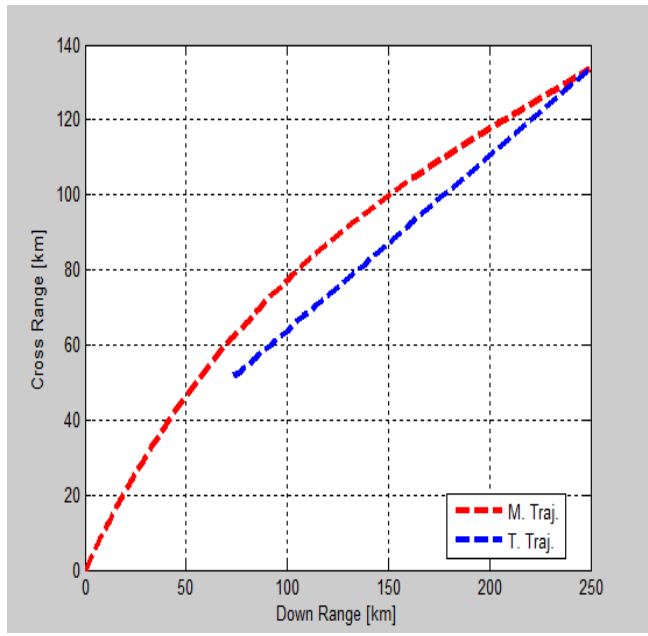

Figure4: Trajectories of missile and target with interception point.

\section{CONCLUSION}

By proofing kinematic equations of motion. We can describe flight path trajectory for our model aerospace vehicle for both translation and rotational motion also showing impact point between our model and the target based on pure pursuit guidance method . Finally we simulate the trajectory by using MATLAB program .

\section{REFERENCES}

[1] Tim Crosby, "RQ-1 Predator," The Warfighter Encyclopedia, California, 2004.

[2] Andreas Parsch, "AeroVironment FQM-151 Pointer," Directory of U.S. Military Rockets and Missiles, 2004, http://www.designation-systems.net/dusrm/m-151.html

[3] Nuke Newcome, "News Room," UAV Forum, SRA International, 4 Oct. 2003,http://www.uavforum.com/library/news.htm.

[4] John Pike, "Dragon Eye" Intelligence Resources, GlobalSecurity.org, 21 Dec. 2003,

[5] Pitman, G.R., Jr. (ed.): Inertial Guidance, 1962

[6] Laur, T.M. and Llanso, S.L. (edited byW.J. Boyne): Encyclopedia of Modern U.S. MilitaryWeapons, Berkley Books, New York, NY, 1995.

[7] Blakelock, J.H.: Automatic Control of Aircraft and Missiles, John Wiley \& Sons, Inc., New York, NY, second edition, 1991.

[8] George M. S. : Missile Guidance and Control Systems, Springer-Verlag New York, Inc. 2004.

[9] Garnell, P.: GuidedWeapon Control Systems, Pergamon Press, Oxford, NewYork, second edition, 1980

[10] Whitaker, H.P., Yarmon, J., and Kezer, A.: Design of Model-Reference Adaptive Control Systems for Aircraft, Instrumentation Laboratory, M.I.T., Report R-164, September 1958.

[11] Clarinval, Andrh, Esquzsse histon'que de la courbe de poursuite,UNESCO-Archives internationales d'histoire des sciences, Vol. 10(38), 1957, pp. 25-37.

[12] Bernhart, Arthur, "Curves of Pursuit", Scripta Mathernatica, Vol. 20, 1954, pp. 125-141

[13] Bernhart, Arthur, "Polygons of Pursuit", Scripta Mathernatica, Vol. 24, 1959, pp. 23-50.

[14] Good, I. J., "Pursuit Curves and Mathematical Art", Mathematical Gazette, Vol. 43, 1959, pp. 34-35.

[15] Gardner, Martin, "Mathematical Recreations", Scientific American, July 1965.

[16] Bruckstein, Alfred M., "Why the Ants Trails Look so Straight and Nice", The Mathematical Intelligencer, Vol 15, No. 2, 1993, pp. 59-62. 